\title{
The Relationship between Emotional Quotients, Socioeconomic Status and Performance in Reading Comprehension: A Case Study of Iranian High School Students
}

\author{
Mohammad R. Talebinejad \\ Islamic Azad University, Shahreza Branch, Iran \\ Email: talebinejad@iaush.ac.ir \\ Zahra Rezai Fard \\ Islamic Azad University, Shahreza Branch, Isfahan, Iran
}

\begin{abstract}
The main purpose of this study was to investigate the relationship between emotional quotient (EQ) and socioeconomic status and their effect on the performance of EFL learners in reading comprehension at high school. To this end, 80 homogenous EFL female students were selected from different high schools in Eghlid with the age range of 14-17. The participants were asked to complete Quick Placement Test, the "Emotional Intelligence Questionnaire", and the "Socioeconomic Questionnaire". Moreover, they answered the reading comprehension test. The Data analysis and statistical calculations revealed that there was a significant relationship between the students' emotional intelligence, socioeconomic status and their reading ability.
\end{abstract}

Index Terms-Emotional Quotient (EQ), socioeconomic status (SES), reading (process), comprehension, intelligence

\section{INTRODUCTION}

The earliest roots of emotional intelligence can be traced to Darwin's work on the importance of emotional expression for survival and its second adaptation. The concept of Emotional Quotient (EQ) formally developed out of growing emphasis on research on the interaction of emotion and thought in the field of psychology in 1990s (Grewal \& Salovey, 2005). Recently, more attention has been paid to the effect of emotions and utilizing the power or information contained in emotion to make effective decisions (Ciarrochi \& Mayor, 2007). EQ or EI is about the intelligent use of emotions and utilizing the power or information contained in emotion to make effective decisions. This study tried to shed some light on the studies regarding emotional intelligence and socioeconomic status, which are important factors involved in the process of second or foreign language learning.

In the present study the writer tried to analyze the relationship between EQ and SES on performance in reading comprehension. If the researcher considers EQ in a reading text and also considers socioeconomic status, she may find out their impact on learning. The scientific research of twenty years on emotional intelligence clearly shows that it is a vital and significant indicator of overall success in life and a necessary part of manifesting our human potentials.

\section{STATEMENT OF THE PRoblem}

As Gardner (2006) states, to understand fully the complexity of language learning process, should pay attention to internal mechanisms and social interpersonal interaction involved in this process. To this end emotional Quotient can be a great help since, as Goleman (2001) states, it not only servers as an internal mechanism, but also interlocks with the external environment. Gardner (1993) emphasizes that language is not grammar specific influenced by other factors that are intelligence based. In the same line, he has expanded the framework of traditional intelligence and emphasized the development of language is not limited to syntax, semantic and phonology.

In this study, the writer tried to investigate the relationship between EQ and socioeconomic status on performance in reading, since there was no study in this area, especially regarding reading comprehension. However, EQ measures the emotional quotient of an individual. It measures the ability of an individual to use his cognitive and emotional intelligence to succeed in life- both personally and professionally. It measures concepts like intuition, empathy, stress management capacities, resilience and integrity. As Horvard (1983) states, EQ can be improved upon and learned. It also consists of five key skills, each building on the last, 1) the ability to quickly reduce stress, 2) the ability to recognize and manage your emotions, 3) the ability to connect with others in using nonverbal communication, 4) the 
ability to use humor and play to deal with challenges, and 5) the ability to resolve conflicts positively and with confidence.

Salovey and Mayer (1990) have been the leading researchers on emotional intelligence. In their influential article Emotional Intelligence, they defined emotional intelligence as "the subset of social intelligence that involves the ability to monitor one's own and others' feelings and emotions, to discriminate among them and to use this information to guide one's thinking and actions" (Salovey \& Mayor, 1990). Salovey and Mayer (1998) proposed a model that identified four different factors of emotional intelligence: the perception of emotion, the ability to reason using emotions, the ability to understand emotion, and the ability to manage emotions. According to Salovey and Mayer, the four branches of their model are, "arranged from more basic psychological processes to higher, more psychologically integrated processes. For example, the lowest branch concerns the (relatively) simple abilities of perceiving and expressing emotion. It is a term used to measure how much you understand your inner self and the tasks you can perform satisfactorily without getting stressed or depressed.

Gardner's Frames of Mind: The Theory of Multiple Intelligences (1983) introduced the idea of multiple intelligences which included both interpersonal intelligence (the capacity to understand the intentions, motivations and desires of other people) and intrapersonal intelligence (the capacity to understand oneself, to appreciate one's feelings, fears and motivations). In Gardner's view (1983), traditional types of intelligence, such as IQ, fail to fully explain cognitive ability. Thus, even though the names given to the concept varied, there was a common belief that traditional definitions of intelligence are lacking in ability to fully explain performance outcomes. Intelligence is ability and is directly measured only by having people answer questions and evaluating the correctness of those answers.

\section{RESEARCH QUESTION AND HYPOTHESIS}

With regard to what was said above, this study tried to seek an answer to the following question:

What is the relationship between emotional intelligence, socioeconomic status, and reading comprehension?

According to the above question, the following null hypothesis was posed to be tested in this study:

Ho: There is no relationship between emotional intelligence, socioeconomic status, and reading comprehension.

\section{METHODOLOGY}

\section{A. Participants}

In the initial phase, 100 high school female students with the age range of 14-17 participated in Quick Placement Test, which is a reliable and valid test, in order to select a homogeneous group as pre-intermediate learners of English language. Those who scored between 28 and 36 (eighty homogeneous female learners) were selected and the rest were omitted from the study. These participants were included in four intact classes in high schools.

\section{B. Instrumentation}

This study made use of the following materials for data collection.

\section{The Quick Placement Test}

In order to control the proficiency factor, there was a need to homogenize the participants according to their level of L2 proficiency. To do so the Quick Placement Test (QPT) was used to select the pre-intermediate group. The test consists of 60 questions. There were five questions related to their knowledge of different signs and notices used to indicate particular meanings, five cloze passages (25 questions), 20 multiple-choice questions which assessed the participants' knowledge of grammar, 10 multiple choice questions related to the knowledge of vocabulary.

\section{Emotional Intelligence Questionnaire. Bar-On, R. (2004)}

Although the EQ-i is the first test of emotional intelligence to be published by a psychological test publisher, it may more accurately be described as a self-report measure of emotionally and socially competent behavior which provides an estimate of one's emotional and social intelligence (EMONET digest 403, May 2000). Bar-On in his manual book The Handbook of Emotional Intelligence regarded EQ measure "an array of noncognitive capabilities, competencies, and skills that influence one's ability to succeed in coping with environmental demands and pressures" (Bar-On, 1997).

As Bar-On acknowledges, the EQ-i is a self-report test. As with all self-report tests, it relies on the test takers' honesty and accurate self-knowledge when it comes to test questions like 'I am able to identify my feelings', 'I like anyone I meet', 'Others can hardly depend on me'. Bar-On (1997) maintains that,

A concern I have with such tests, and to a lesser extent even with the Mayer et al.'s tests, is that someone who is smart, dishonest and who has a little knowledge of emotional intelligence literature could relatively easily figure out the 'correct' answers. To my amusement I have noticed that the researchers have a polite way of referring to someone who deliberately lies on such a self-report test. They call it "impression management"!

The questionnaire consists of 130 questions in order to measure global trait emotional intelligence. In this questionnaire emotional intelligence is divided into four factors: (a) sociability (social skills), (b) emotionality (emotion skills), (c) self-control, and (d) well being. The self-report questionnaire is a Likert scale coded on a 5-point scale ranging from "strongly agree" (5), which indicates highest degree of its presence to "strongly disagree" (1), which indicates the lack of construct. For instance, a participant who selects 'strongly agree' alternative, upon reading "It's 
easy for me to talk about my feelings to other people" is considered more emotionally intelligent than a participant who selects 'strongly disagree' or 'disagree' alternatives.

\section{Socioeconomic Status Questionnaire}

This questionnaire was used in order to measure the socioeconomic status of the participants. The questionnaire consisted of 11 questions including questions about the participants' family income, education, sociability with their friends and relatives, and communication with others in case of difficulties. This questionnaire was also in the form of Likert scale with 1 being the lowest and 4 being the highest.

\section{Reading Comprehension Tests}

In order to measure the ability of students in reading, the researcher used a test with three passages with the difficulty level as their school textbook. The passages were about a plane crash in Switzerland, learning a language, and working to pay for university. The test consisted of 11 multiple-choice questions and measured the students' ability in reading comprehension.

\section{Procedures}

In the beginning of the experiment, two girl high schools in Eghlid, Fars Province were selected. There were 100 students in these two schools. In order to select a homogeneous group, a QPT was administered and those who scored between 28 and 36 were selected as the pre-intermediate students. In order to make sure that the students have been not tired of taking part in the experiment, each part was administered in one session with a week interval. Therefore, one week after the placement test, the EQ questionnaire was given to them to complete. In the third week, the socioeconomic questionnaire was administered to them to answer. It should be mentioned that for both questionnaires the students were given enough time to complete all the questions. Finally, in the fourth week, the reading comprehension test was given to the participants. After that all the questionnaires were analyzed and the reading comprehension test papers were corrected for the purpose of data analysis.

\section{RESUltS}

\section{A. Emotional Intelligence Questionnaire}

After collecting these questionnaires, it was analyzed and graded appropriately according to the original test criteria (Bar-On, 1997). Table 4.1 reveals the descriptive statistics for this questionnaire and Figure 4.1 illustrates the graphical representation of the frequencies in bar format.

TABLE 4.1

\begin{tabular}{lllll}
\multicolumn{5}{c}{ DESCRIPTIVE STATISTICS FOR THE EMOTIONAL INTELLIGENCE QUESTIONNAIRE } \\
\hline No. & Min & Max & Mean & SD \\
\hline 80 & 150.00 & 391.00 & 258.90 & 55.289 \\
\hline
\end{tabular}

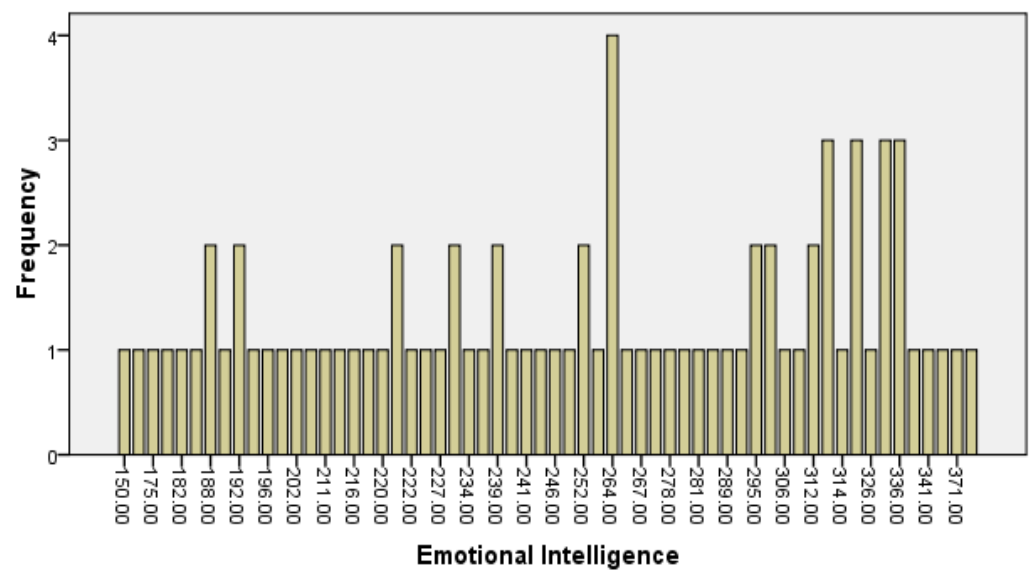

Figure 4.1.The Graphical Representation of the Frequencies for the Emotional Intelligence Questionnaire

As it can be seen in Figure 4.1, the grades are highly dispersed among the participants and vary between 150 and 371 which mean the population under study includes a wide range of emotional intelligence.

B. Socioeconomic Status Questionnaire 
After the participants completed this questionnaire, the researcher collected the questionnaires and analyzed and interpreted the results. Table 4.2 indicates the descriptive statistics for this questionnaire and Figure 4.2 is the graphical representation of the frequencies.

TABLE 4.2

DESCRIPTIVE STATISTICS FOR THE SOCIO-ECONOMIC STATUS QUESTIONNAIRE

\begin{tabular}{lllll}
\hline No. & Min & Max & Mean & SD \\
\hline 80 & 18.00 & 40.00 & 28.95 & 5.170 \\
\hline
\end{tabular}

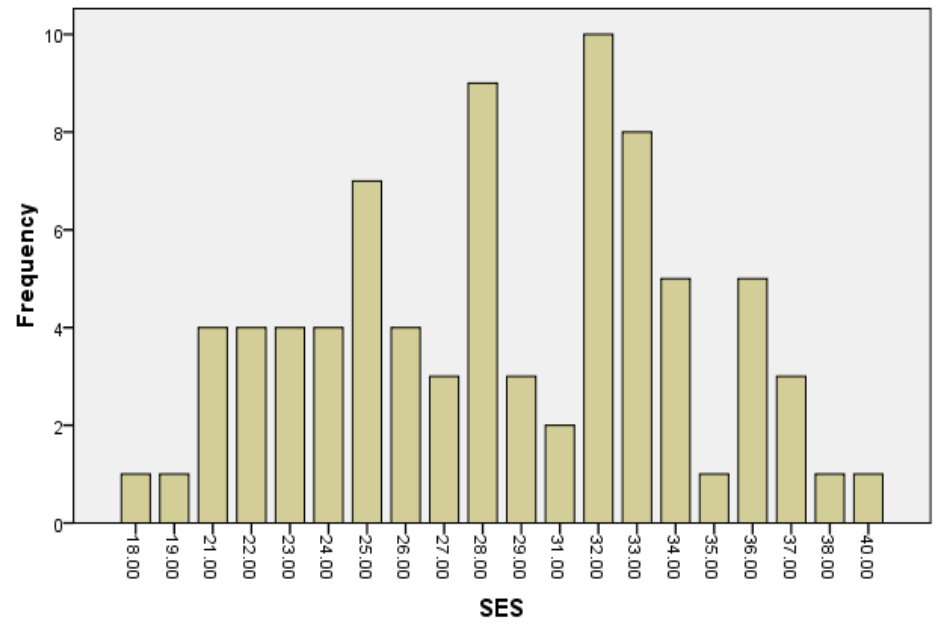

Figure 4.2.The Graphical Representation of the Frequencies for the Socioeconomic Status Questionnaire

As with emotional intelligence questionnaire, the results of this questionnaire also represent a wide range of participants with different socioeconomic status.

\section{Reading Comprehension}

In the last stage of the experiment the reading comprehension test was administered. Then the papers were collected and scored by the researcher. Table 4.3 shows the descriptive statistics for this test, and Figure 4.3 indicates the frequencies of the scores in bar form.

TABLE 4.3

DESCRIPTIVE STATISTICS FOR THE READING COMPREHENSION TEST

\begin{tabular}{lllll}
\hline No. & Min & Max & Mean & SD \\
\hline 80 & 4.00 & 11.00 & 7.38 & 1.938 \\
\hline
\end{tabular}

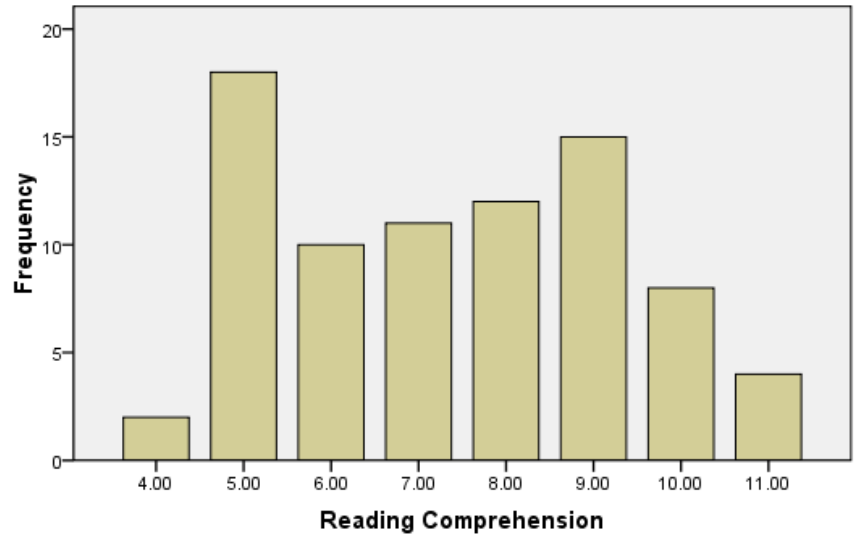

Figure 4.3.The Graphical Representation of the Frequencies for the Reading Comprehension Test

The reading comprehension scores also include a variety of scores ranging between 4 and 11; in other words, the participants varying their reading comprehension ability.

D. The Results of the Correlational Analysis 
The next step after collecting the necessary data was to see if there is any correlation between different pairs of data, that is, emotional intelligence and socioeconomic status, emotional intelligence and reading comprehension, and finally socioeconomic status and reading comprehension.

First, the correlation between emotional intelligence and socioeconomic status was calculated. Table 4.4 indicates the results of this correlation.

TABLE 4.4

THE RESUlTS OF THE CORRELATION BETWEEN EMOTIONAL INTELLIGENCE AND SOCIOECONOMIC STATUS

\begin{tabular}{lll}
\hline & & SES \\
\hline EI & Pearson Correlation & $.715^{* *}$ \\
& Sig. (2-tailed) & .000 \\
& $\mathrm{~N}$ & 80 \\
\hline
\end{tabular}

**. Correlation is significant at the 0.01 level (2-tailed).

$\mathrm{EI}=$ Emotional Intelligence

$\mathrm{SES}=$ Socio-economic Status

It can be seen in Table 4.4 that the correlation between emotional intelligence and socioeconomic status is .715 which is significant at the probability level of .000 , which denotes a high correlation between these two variables.

Second, the correlation between emotional intelligence and reading comprehension was calculated. Table 4.5 indicates the results of this second correlation.

TABLE 4.5

THE RESULTS OF THE CORRELATION BETWEEN EMOTIONAL INTELLIGENCE AND READING COMPREHENSION

\begin{tabular}{lll}
\hline & Reading Comprehension \\
\hline EI & Pearson Correlation & $.798^{* *}$ \\
& Sig. (2-tailed) & .000 \\
$\mathrm{~N}$ & 80 \\
\hline \multirow{3}{*}{$* *$. Correlation is significant at the 0.01 level (2-tailed). } \\
\multicolumn{2}{c}{ EI= Emotional Intelligence }
\end{tabular}

According to Table 4.5, the amount of correlation between emotional intelligence and reading comprehension is also high $(r=.798)$ and is significant at the probability level of .000 . Once again it can be said that these two criteria are also highly correlated.

Finally, the correlation between socioeconomic status and reading comprehension was determined. Table 4.6 depicts the results of this last correlational analysis.

TABLE 4.6

THE RESUltS OF THE CORRELATION BETWEEN SOCIOECONOMIC STATUS AND READING COMPREHENSION

\begin{tabular}{lll}
\hline SES & Pearson Correlation & $.736^{* *}$ \\
& Sig. (2-tailed) & .000 \\
$\mathrm{~N}$ & 80 \\
\hline
\end{tabular}

**. Correlation is significant at the 0.01 level (2-tailed).

$\mathrm{SES}=$ Socio-economic Status

One can see in Table 4.6 that, as with the other two correlations, this correlation is also high $(\mathrm{r}=.736)$ which is significant at the probability level of .000; in other words, these two variables are also highly correlated.

According to the results of the three correlational analysis presented above, it can be said that the null hypothesis can safely be rejected, and it can be claimed that there is a positive relationship between emotional intelligence and socioeconomic status, emotional intelligence and reading comprehension, and socioeconomic status and reading comprehension.

\section{DISCUSSION}

The results described in the previous chapter show the positive relationship between emotional intelligence and socioeconomic status and their effect on reading comprehension. The studies empirically support the positive relationship between EI, on the one hand, academic status (Besharatno et al., 2005; Stottlemayer, 2006), second language performance (Pishghadam, 2007), language learning strategy use (Aghasafari, 2006), academic success (Bozorgmehr, 2008), reliability and validity of EQ-I (Dehshiri, 2005), and self-efficiency (Ghanizadeh \& Moafian, 2009), on the other hand. Higher socioeconomic background may attenuate children's long term academic difficulties with learning disabilities, with or without intervention (Telzrow, 1987).

The results from previous studies interpreted that EI is important for work settings (Carmeli, 2003), classrooms (Petrides, Frederickson, \& Furnham, 2004) and contextual performance (Carmeli, 2003). EI predicts positive social and academic outcomes in children (Eisenberge et al., 2000, Schultz et al., 2004). Gardner (1993) states that in order to 
understand the complexity of language learning process fully, we should pay attention to internal mechanisms and social interpersonal interactions involved in this process. The studies in the area of psychology support the positive relationship between EQ and second language performance, emotional intelligence can partly learned, however this study fail empirical evidence on how to improve EQ in the EFL context.

This is the point this study can significantly touch upon through the results obtained. Also, it is stated that EI consistently predicts positive social and academic outcomes (Eisenberge et al., 2000, Schulte et al., 2004), and positively predicts social skills such as assertion, cooperation, and self-control (Izard et al., 2002). The studies in the area of socioeconomic status in literature empirically support the positive correlation between SES and second language achievement and children's development (Humphrey, Farquhar, \& Stein, 1993). SES has a systematic effect on reading skills, and the social context of language learning has powerful influence on language learning (Stern, 1998, p. 269).

\section{CONCLUSIONS}

In this study, 80 homogenous female students (intermediate level) were selected after the Quick Placement Test administration and were subjected to the Bar-On Emotional Questionnaire, SES Questionnaire and three reading comprehension texts. The correlation between these Questionnaires was analyzed by SPSS. The major findings are summarized below.

First, the higher scores on reading comprehension show higher scores on SES, higher scores on EI show higher scores on reading comprehension, and finally, higher scores on SES show higher scores on EI, and vice versa, This study provides empirical evidences that socioeconomically-disadvantaged factors affect on learner's performance, the higher the socioeconomic status related to the higher learning performance and also this study presents evidences about relationship between EI, SES and reading comprehension. The relationship between EI and SES has had a large effect on reading comprehension (Report of the National Reading Panel, 2000). Higher socioeconomic background reduced learning difficulties. However, it is imperative that the effects of EQ variables (achievement motivation, flexibility, happiness) be examined in the context of a child's socioeconomic background. SES modulates the relationship between education performance and learning and has several important implications for education. Language learning can gain momentum through better socioeconomic status and improving the EI. EFL learners can enjoy communicative facility and experience high levels of emotional quotient and socioeconomic status if teachers rely on emotion-generating and emotion-managing techniques and pay attention to their social and economic status. In addition, some teachers and learners can appropriately tackle some of the affective and communication problems besetting in the classrooms and evaluate learners' language performance in an optimistic light, leading to better L2 learning performance. The empirical findings of the study on emotional intelligence and socioeconomic factors enable one to argue for the following pedagogical implications. Given that students can learn by observing symbolic and representing modeling, EI-based syllabuses can come into action with many liberal arts such as poetry, drama and stories. Young learners can learn much about their feelings when they read literary excerpts that depict characters with tendency to experience specific emotions.

Also, this study provided the empirical evidence for the therapeutic role of emotional intelligence and socioeconomic status in foreign language learning. EQ can be improved upon and learned, students can reduced their stress, recognize and also manage their emotions. It has also provided evidences about the relationship between EQ and SES, if socioeconomic status improved, students received high EQ and both teachers and learners can appropriately remove affective and communication problems affect their language performance and learning in the classroom. The teachers can use tool and strategies to investigate EQ skills of students in class, so based on they can to promote their learning performance and use some strategies for improving their socioeconomic status. They can also orient a curriculum towards helping students identify their own feelings and their own feeling to others so they can think rationally and preformed better in learning.

\section{REFERENCES}

[1] Aghasafari, M. (2006). On the relationship between emotional intelligence and language learning strategies. MA Thesis, Allameh Tabatabaei"ii University, Tehran.

[2] Besharat, M. (2005). The relationship between EQs and mental health. MA Thesis, Allameh Tabataba'ii University, Tehran.

[3] Bar-On, R. (1997). The Bar-On Emotional Quotient Inventory (EQ-I): A test of emotional intelligence. Toronto, Canada: Multi-Health Systems.

[4] Bar-On, R. (2000). Emotional and social intelligence: Insights from the emotional Quotient inventory (EQ-i). In R. Bar-On \& J. C. A. Parker (Eds.), Handbook of emotional intelligence. San Francisco: Jossy-Bass.

[5] Bozorgmehr, M. (2008). On the relationship between emotional intelligence and academic success. MA Thesis, Khorasgan University, Isfahan.

[6] Carmeli, A. (2003). The relationship between emotional intelligence and work attitudes, behavior and outcomes: An examination among senior managers. Journal of Managerial Psychology, 18, 788-813.

[7] Ciarrochi, J; Mayor, J. (2007). Applying emotional intelligence. A practitioner's guide: New York. Cambridge University Press

[8] Dehshiri, R. (2003). The Reliability and Validity of EQ-I in Iran's Context, Unpublished Master's Thesis. Allame Tabatabaee University, Tehran, Iran.

[9] Eisenberge, N. (2000). "Emotion. Regulation, and moral development". Annual Review of Psychology. 51, 665-97. 
[10] Gardner, H. (1993). Frames of Mind. New York: Basic Books.

[11] Gardner, L., \& Stough, C. (2006). Examining the relationship between leadership and emotional intelligence in senior level managers. Leadership \& Organization Development Journal, 23, 68-78.

[12] Ghanezadeh, A., \& Moafian, F. (2009). The relationship between Iranian EFL teachers' emotional intelligence and their selfefficiency in Language institutes. The Journal of Social Psychology, 37, 708-718.

[13] Goleman, D. (2001). Emotional intelligence: Issues in paradigm building. In C. Cherniss\& D. Goleman (Eds.), The emotionally intelligent workplace (pp. 182-206).San Francisco: Jossey-Bass.

[14] Grewal, D; Salovey, P (2005)."Feeling smart. The science of emotional intelligence". American Scientists 93, 330-339.

[15] Huphery, D. C., Farquhar, E., \& Stein, S. E. (1993). Review of Research on Achiveing the nation's readiness goal. Washington, DC: US. Department of Education.

[16] Izard, C. E. (2002). Translating emotion theory and research into preventive interventions. Psychological Bulletin 128, $796-824$.

[17] Petrides, K. V., Frederickson, M., \& Furnham, A. (2004). The role of trait emotional intelligence in academic performance and deviant behavior at school. Personality and individual Differences, 35, 277-293.

[18] Pishghadam, R. (2007). On the influence of emotional and verbal intelligence on second language learning. Pd. D. Thesis, Allameh Tabataba'ii University, Tehran.

[19] Report of the National Reading Panel. (2000). Washington, DC: National Institute of Child Health and Human Development.

[20] Salovey, P., \& Mayer, J. (1989-90). Emotional Intelligence. Imagination. Cognition and Personality, 9, $185-211$.

[21] Salovey, P., Mayor, J. D. (1990). Emotional intelligence. Imagination, Cognition, and Personality, 9, 85-211.

[22] Salovey, P., Mayer. J. D., \& Caruso, D. (2002). The positive psychology of emotional intelligence. In C. R. Snyder and S. J. Lopez (Eds.), Handbook of Positive Psychology (pp. 159-171). New York: Oxford University Press.

[23] Salovey, P., Mayer, J. D., Goldman, S. L., Turvey, C., \& Palfai, T. P. (1998). Emotional attention, clarity, and repair: Exploring emotional intelligence using the Trait Meta-Mood Scale. In J. W. Pennebaker (Ed.), Emotion, disclosure and health. Washington, DC: American Psychological Association.

[24] Schulte, M. J., Ree, M. J., \& Carretta, T. R. (2004). Emotional intelligence: Not much more than $g$ and personality. Personality and Individual Differences, 37, 1059-1068.

[25] Stern, H. H. (1998). Fundamental Concepts of language teaching. Oxford: Oxford University Press.

[26] Stottlemayor, (2006). "Emotional Intelligence and academic success." Journal of Reading, 37(5), 320_329.

[27] Telzrow, C. F. (1987). The So what? question: Intervention with learning disabled children. In J. M. Williams \& C. J. Long (Eds.), The rehabilitation of cognitive disabilities (pp. 191-205). New York: Plenum Press.

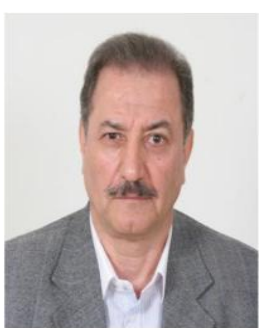

Mohammad R. Talebinejad is an Associate Professor of Applied Linguistics at Islamic Azad University, Shahreza Branch. He is also an associate faculty member at Sheikhbahaee University, Iran. Dr Talebinejad received his BA in English Language and Literature, University of Isfahan in 1975. He then got his MA in TEFL from the University of Texas at Austin, USA in 1977. For his doctoral degree, Dr Talebinejad was admitted to the University of Sheffield, UK, where he did his PhD in Applied Linguistics in 1994.

He has widely published in Iranian as well as International professional journals such as Metaphor and Symbol, English Teaching Forum, Language Testing, IJAl, Language and Translation, Journal of Social Sciences, The International Journal of Humanities, and other local and international journals. Dr Talebinejad has presented papers in International conferences such as AILA, 2000; Atiner, 2011; RAAM, 2002, 2001 in Paris and Tunis, EUROSLA, Switzerland, 2006; Multicultural Conference, 2007, China. In addition, Dr Talebinejad has authored/coauthored eight books in related fields and ESP.

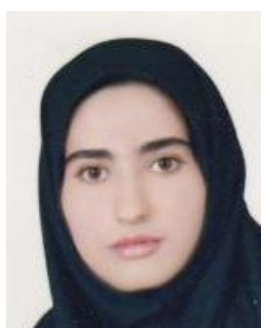

Zahra Rezaei Fard was born in Eghlid city, Fars Province. She received her BA in translation from Islamic Azad Abadeh University, Iran in 2008. She then got MA in TEFL from IAUSH in 2011. Ms REzaei Fard is currently teaching English in language institutes in Iran. 